\title{
UMA ANÁLISE SOBRE AS ASSOCIAÇÕES DE USUÁRIOS DE DROGAS DAS REGIÕES SUDESTE E CENTRO-OESTE A PARTIR DO CIBERATIVISMO ${ }^{1}$
}

Júlio César Paiva e Silva UFPI²

Lucia Cristina dos Santos Rosa UFPI/CSS

\section{RESUMO}

A partir da pesquisa A participação da família no processo de desinstitucionalização em saúde mental, a partir do ciberativismo, recortou-se o tema do consumo de substâncias psicoativas. As indagações que levaram à implementação da pesquisa giram em torno de: como se identificam e se caracterizam as associações de familiares no espaço virtual? Que necessidades em saúde mental veiculam? O ciberativismo contribui para maior visibilização das necessidades dos familiares cuidadores, a partir de marcadores de classe social, gênero e etnia? Tem por objetivo geral: analisar a configuração da participação da família no processo de desinstitucionalização, a partir do ciberativismo e dos marcadores de classe social, gênero e etnias, no período de 1990 a 2018. A importância da mesma se situa na maior visibilização e equacionamento das necessidades da família, no contexto do consumo de substâncias psicoativas. A metodologia da pesquisa é fundamentada em pesquisa qualitativa, com triangulação de fontes, tendo por principais ferramentas: a análise documental, bibliográfica, a pesquisa nos sítios virtuais das associações de usuários e familiares. Os achados e as conclusões sinalizam para a prevalência das necessidades dos usuários, com visibilização apenas das questões raciais quando as associações são explicitamente contrárias às políticas de guerra às drogas, com parcas convocações e explicitações das necessidades da família.

Palavras-Chave: Ciberativismo. Cidadania. Família. Desinstitucionalização. Álcool e Drogas.

\section{INTRODUÇÃO}

O movimento da Reforma Psiquiátrica no Brasil configura-se como importante marco para a construção da cidadania da pessoa com transtorno mental, na política de saúde mental, organizado e articulado entre vários segmentos sociais - trabalhadores, usuários, familiares, defensores dos direitos humanos, entre outros - que garantiu o fortalecimento do protagonismo dos sujeitos

\footnotetext{
${ }^{1}$ Trabalho apresentado no Congresso Brasileiro Ciência e Sociedade (CBCS 2019), promovido pelo Centro Universitário Santo Agostinho, de 03 a 05 de outubro de 2019, em Teresina-PI.

${ }^{2}$ Júlio César Paiva e Silva: Estudante do Curso de Serviço Social da UFPI. ICV UFPI. E-mail: juliomcps@gmail.com.

${ }^{3}$ Lucia C.S. Rosa: Pós Doutorado em Saúde Coletiva Unicamp. Doutorado em Serviço Social. Programa de Pós

Graduação em Políticas Públicas. E.mail: luciacsrosa@gmail.com. 
ANAIS CBCS 2019 | 3 a 5 de outubro de 2019 | Centro Universitário Santo Agostinho - Teresina - PI

atingidos pela política manicomial. É importante destacar que o público dos hospitais psiquiátricos não era restrito àqueles com transtornos mentais graves ou persistentes. Daniela Arbex, ao analisar um grande hospital psiquiátrico do país, aponta que, em relação aos usuários:

Cerca de 70\% não tinham diagnóstico de doença mental. Eram epiléticos, alcoolistas, homossexuais, prostitutas, gente que se rebelava, gente que se tornara incômoda para alguém com mais poder. Eram meninas gravidas, violentadas por seus patrões, eram esposas confinadas para que o marido pudesse morar com a amante, eram filhas de fazendeiros as quais perderam a virgindade antes do casamento. Eram homens e mulheres que haviam extraviado seus documentos. Alguns eram apenas tímidos. (ARBEX, 2013, p. 14)

As articulações que resultaram na Reforma Psiquiátrica iniciam-se em torno das situações trabalhistas, com o Movimento dos Trabalhadores da Saúde Mental (MTSM), mas logo ampliam-se com a participação de outros segmentos da sociedade civil, influindo na construção de um pensamento crítico capaz de proporcionar a visualização de possibilidades de substituição ao modelo hospitalocêntrico, fortalecendo a cidadania e o cuidado comunitário.

Dessa forma, considerando a influência das condições sociais no processo saúde-doençacuidado, a desinstitucionalização surge como importante mecanismo para a reinserção social e comunitária dos sujeitos até então segregados. Com mudanças nas esferas técnica, administrativa, jurídica, legislativa, ética e política, a Reforma Psiquiátrica reconhece o direito das pessoas com transtorno mental, inclusive os consumidores de substâncias psicoativas.

A desinstitucionalização considerada como sinônimo de cidadania e de reforma psiquiátrica, no contexto brasileiro fundamentou-se na experiência italiana, pautando a autonomia e emancipação dos usuários. Logo a desinstitucionalização ocorreu pari passu ao fortalecimento da formação político-social dos sujeitos, sendo sua pré-condição. A participação em fóruns, assembleias, espaços comunitários e audiências públicas é estimulada e garante a articulação entre os diversos movimentos que pontuam a luta por direitos humanos, civis e sociais, além da participação nas arenas decisórias na formulação, implementação e avaliação de políticas públicas.

A atenção voltada aos consumidores de substâncias psicoativas, até então tema exclusivo da Segurança Pública, entra na agenda da saúde pública. Antes considerada questão de problema 
ANAIS CBCS 2019 | 3 a 5 de outubro de 2019 | Centro Universitário Santo Agostinho - Teresina - PI

moral, tendo como tratamento a punição e exclusão em manicômios, sem qualquer diferenciação entre usuários dependentes ou não e o traficante, a atenção ao usuário passa por transformações a partir desse processo, com a substituição do modelo biologizante que tem o foco nas substâncias. Os diferentes padrões de consumo ganham destaque, assim como a complexificação da relação substância, o indivíduo e o contexto social, com o objetivo de defender e reinventar a vida.

Costa (2012, p. 406), destaca que:

A partir de 2002, o Ministério da Saúde assume essa questão como um problema de saúde pública, regulamentando um serviço denominado de Centro de Atenção Psicossocial para Usuários de Álcool e outras Drogas (CAPS-ad), um serviço de base territorial e comunitária, com a proposta de tratamento espontâneo em que a lógica da abstinência foi abolida.

A Política de Atenção Integral a Usuários de Álcool e outras Drogas, criada em 2003 pelo Ministério da Saúde, seguida pela regulamentação da Política de Redução de Danos através do decreto no 1028 em 2005, são outros dois importantes pontos na disputa entre a esfera da saúde e da segurança pública no que diz respeito a atenção aos consumidores de spa. Esses marcos garantem a possibilidade de oferecer diferentes tipos de tratamentos aos diferentes tipos de usuários, considerando as particularidades de cada sujeito, de forma que sejam tratados dignamente e com respeito.

A regulamentação da Redução de Danos fortalece a autonomia dos usuários de substâncias psicoativas pois estimula a informação para garantir a prevenção e compartilha a responsabilidade entre usuário e Estado na produção do cuidado. Aqueles que desenvolvem dependência de substancias consideradas proibidas, como cocaína, crack, heroína, entre outras, encontram mais dificuldades na hora de procurar ajuda, até pelo preconceito. Por estarem no campo de batalha entre saúde pública e segurança pública, apesar de possuírem direitos aos serviços públicos de saúde, são geralmente discriminados, tratados como criminosos, a partir de um discurso estigmatizante e culpabilizador. Costa (2012) destaca que o tratamento para usuários de drogas torna-se subordinado à lógica punitivista, que apresenta a abstinência como única meta possível. Ao combater esse posicionamento, a política de Redução de Danos possibilita a garantia de direitos aos usuários que não querem, não podem ou não conseguem atingir a abstinência. Isso fortalece o 
ANAIS CBCS 2019 | 3 a 5 de outubro de 2019 | Centro Universitário Santo Agostinho - Teresina - P

protagonismo desses sujeitos, e possibilita sua organização política, estimulando a autonomia e desmistificação na relação entre homem e substancia.

A Lei no 11.343 de 23 de agosto de 2006 foi bastante significativa para a garantia de direitos e possibilidade de organização dos usuários das substâncias consideradas ilícitas. Substituindo a Lei no 6.368, de 21 de outubro de 1976, conhecida como Lei dos Entorpecentes, a Lei de drogas apresenta mudanças significativas ao diferenciar traficante de usuário. Dessa forma, ao mudar o tratamento com usuários, contribui para diminuição do estigma, ao tempo que fortalece a articulação entre os mesmos para participação social

Entretanto, é importante destacar que a referida lei também é responsável pela expansão do encarceramento em massa no país, e que a diminuição do estigma está associada também a classe social e raça do usuário. Além do preconceito e violência policial sofrida por usuários negros e pobres, também é muito comum a prisão destes como traficantes.

Com a Lei 8.142/90 que fomenta o controle social, ou seja, a participação dos usuários na formulação, implementação e avaliação de políticas públicas, são estimuladas a criação das associações de usuários e familiares da saúde mental, que se caracterizam como importante mecanismo na formação da autonomia, pois garante participação na complexa arena de decisões da saúde mental, organizando e participando de debates, fazendo com que aspectos importantes entrem na agenda da política do campo. Essas associações proporcionam o reconhecimento do capital social dos sujeitos, estimulando seu protagonismo, visto que "ao participar efetivamente dos problemas do seu mal-estar psíquico, parece propiciar a construção/consolidação de uma consciência social do problema" (AMARANTE, 2001, p. 935)

O impacto causado pelas associações é substancial e garante que as vozes das pessoas afetadas sejam ouvidas e consideradas. Nesses aspectos, as associações também se configuram como articulação e organização dos usuários e familiares da saúde mental, sendo uma questão que merece destaque por garantir a participação social a sujeitos alvos das propostas proibicionista, que os considera culpados pela situação em que se encontram. 
ANAIS CBCS 2019 | 3 a 5 de outubro de 2019 | Centro Universitário Santo Agostinho - Teresina - PI

As associações civis na saúde mental representam um grupo de pessoas que estavam excluídas tanto das relações sociais por meio do estigma, quanto dos níveis decisórios das políticas de saúde (AMARANTE, 2001). Dessa forma, as ações políticas desenvolvidas por essas associações fortalecem e são fortalecidas pelo ativismo desses sujeitos, proporcionando a verdadeira participação social em busca da emancipação.

Entre os diferentes tipos de ativismo, o ciberativismo vem se destacando devido a dimensão do seu alcance e a velocidade na socialização de informações. Ganhou força e se expandiu a partir dos protestos denominados de Primavera Árabe que ocorreram em 2010 no norte da África e no Oriente Médio, em que era comum o uso de redes sociais para a difusão de protestos.

No Brasil, o formato se popularizou durante as jornadas de junho, em 2013, com protestos que começaram contra o aumento da tarifa do transporte público, mas que resultaram em diversas demandas, devido a heterogeneidade dos ativistas. A movimentação em torno do ciberativismo também esteve muito presente nas eleições presidenciais de 2018 , tanto com protestos no campo da esquerda, quanto no campo da direita. Além de uma série de ações em torno das "Fake News", caracterizadas como notícias falsas utilizadas de modo metódico com o propósito de propagar e fortalecer certas ideologias.

Pinho (2003) entende a Internet como uma ferramenta de comunicação que se diferencia bastante dos meios de comunicação tradicionais, caracterizando-se como inovadora devido a facilidade de possibilitar a intercomunicação, aumentando o poder comunicativo das pessoas, pois possibilita a transmissão de informações e imagens em tempo real para qualquer parte do planeta. Dessa forma, a utilização das tecnologias digitais como ferramenta para a comunicação, informação e mobilização para o enfrentamento político, social e cultural, caracteriza-se como ciberativismo (MILHOMENS, 2009)

Nesse contexto, a organização de usuários e familiares da saúde mental em forma de associações se caracteriza como importante parte no processo de desinstitucionalização que busca o protagonismo dos sujeitos a partir do fomento da autonomia e da organização política. O presente 


\section{CONQGEESSOCIENCIAESOCIEDADE

ANAIS CBCS 2019 | 3 a 5 de outubro de 2019 | Centro Universitário Santo Agostinho - Teresina - PI

artigo busca analisar a participação social e o posicionamento das associações de consumidores de spa das Regiões Sudeste e Centro-Oeste através do ciberativismo, a fim de identificar suas formas de organização, composição, temas discutidos e defendidos pelos sujeitos, além das principais atividades.

\section{METODOLOGIA}

Para delimitar o objeto de estudo optou-se, primeiro, por realizar uma busca por associações de familiares e usuários de saúde mental e associações de familiares e usuários de drogas de cada estado das regiões escolhidas, através da aba de pesquisa no Google. A pesquisa realizada no site proporcionou uma série de links, divididos entre artigos, documentos, redes sociais e reportagens sobre as associações. Como resultado do primeiro momento foram encontradas 57 associações mencionadas, dispostas entre: São Paulo (20); Rio de Janeiro (09); Minas Gerais (15); Espirito Santo (03); Mato Grosso (02); Mato Grosso do Sul (03); Goiás (03); e Distrito Federal (02), evidenciando predomínio de associações na Região Sudeste, território em que o processo de reforma psiquiátrica teve início.

Após a pré-seleção, foi analisado quais associações relacionavam-se com o tema álcool e outras drogas, destacando-se 17, dispostas entre os estados de São Paulo (04), Rio de Janeiro (03), Minas Gerais (05), Espirito Santo (01), Mato Grosso (01), e Mato Grosso do Sul (01). A partir disso, foram priorizadas as que possuíam site ou algum perfil em redes sociais, que fossem alimentados com maior frequência, para que fosse possível a análise e o estudo do ciberativismo desses grupos, sendo selecionadas seis associações; Associação Cultural Cannábica de São Paulo; Associação de Defesa da Saúde do Fumante - São Paulo; Associação Antialcoólica do Estado de São Paulo; Associação Brasileira de alcoolismo e drogas - Rio de Janeiro; Associação Psicodélica Brasileira - Rio de Janeiro; e Associação Brasileira Comunitária para Prevenção do Abuso de Drogas (Abraço) Minas Gerais. 
ANAIS CBCS 2019 | 3 a 5 de outubro de 2019 | Centro Universitário Santo Agostinho - Teresina - P

Utilizando, também, a pesquisa bibliográfica para analisar documentos e artigos publicados para embasar os dados coletados, houve o estudo das associações selecionadas e de suas ações políticas, compreendendo a dinâmica e as discussões propostas pelos grupos, quais as principais atividades realizadas no ciberespaço, como os segmentos de classe, raça e gênero perpassam por essa discussão, e como acontece a participação da família nessas esferas de discussão.

\section{RESULTADOS E DISCUSSÃO}

As associações apresentam lugar de destaque na desinstitucionalização e garantia do protagonismo dos usuários. Essa participação social possibilita a desconstrução da "ideia de que o pessoal é para ser mantido na esfera privada, reforçando a ideia de que o pessoal é da esfera pública, social" (ROSA, 2017, p. 05). Dessa forma, o ciberativismo aparece como importante ferramenta para a socialização da informação, ampliando a visibilidade e o alcance dos protestos, além da difusão de ideias. Entretanto, é importante destacar que os resultados aqui obtidos não mostram a realidade geral das associações de consumidores de spa, apenas daquelas que encontram-se presentes de alguma forma no ciberespaço, apresentando a possibilidade de exercer o ciberativismo.

Nesse sentindo, observa-se o caso do estado de Minas Gerais, que apesar de apresentar 05 associações consumidores de spa na primeira etapa da pesquisa, apenas 01 possui site ou rede social. A Associação Brasileira Comunitária para Prevenção do Abuso de Drogas - ABRAÇO foi criada em Minas Gerais, no ano de 1985, e atualmente apresenta dois perfis na rede social Facebook, por onde compartilha informações e mensagens. A partir da análise realizada foi possível destacar que não há discussão sobre os aspectos sociais que influenciam na dependência química, resumindo o compartilhamento de informações em mensagens motivacionais e informações sobre parcerias realizadas pela associação. O fluxo de atividades online é lento, visto que as últimas publicações encontradas são de março de 2019. 


\section{CONQGEESSO CIENCIAESOCIEDADE

ANAIS CBCS 2019 | 3 a 5 de outubro de 2019 | Centro Universitário Santo Agostinho - Teresina - PI

As dificuldades na periodicidade de comunicação e alimentação do site também são encontradas na Associação de Defesa da Saúde do Fumante - SP. Sem possuir redes sociais, apresenta apenas um site com informações básicas, como: ano de criação (1995), local da sede, e seção para filiação, sem que seja possível saber até quando o site foi atualizado. Porém, dispõe de textos informativos sobre o hábito de fumar, assim como suas consequências na vida do usuário, fortalecendo sua finalidade: defender os direitos dos fumantes. Não há uma visão culpabilizadora do usuário, sendo percebidos pela associação como vítimas da propaganda enganosa.

Essa visão não-culpabilizadora também é perceptível na análise das atividades e posicionamentos da Associação Antialcoólica do Estado de São Paulo, criada em 1950. Apesar de ter a abstinência como objetivo principal no cuidado, afirma não ser contra quem produz, comercializa ou consome álcool e outras substâncias, pontuando a importância de combater o preconceito e a discriminação por raça, classe ou religião. Suas principais atividades são atendimento psicológico, terapia em grupo e atendimento a usuários de outras drogas além do álcool. No âmbito virtual, disponibiliza vídeos e textos informativos sobre dependência e suas diversas formas de tratamento no site, enquanto o Facebook era utilizado para compartilhamento de informações sobre eventos realizados, entretanto as atualizações na rede social só permaneceram até 2016.

Outra associação de usuários de drogas do estado de São Paulo que foi observada recebe o nome de Associação Cultural Cannábica de São Paulo, e difere-se das supracitadas por ter como foco em uma substância considerada juridicamente ilícita. Apresentando a predominância de ativistas que fazem uso social e terapêutico da substância, a Acuca-SP exerce importante função para a discussão sobre os diferentes tipos de usuário, importante no combate do estigma, visto que geralmente apenas os usuários de substâncias ilícitas são considerados "viciados", sem compreender as pessoas que fazem uso experimental, recreativo ou social.

A associação discute a necessidade de uma sociedade que supere os preconceitos em relação às drogas, através da informação para geração de consciência, respeito e atendimento 
ANAIS CBCS 2019 | 3 a 5 de outubro de 2019 | Centro Universitário Santo Agostinho - Teresina - P

adequado. Dessa forma, fomentam o combate ao estigma e ao preconceito, além de incentivar o protagonismo e respeito ao usuário, apresentando um posicionamento antiproibicionista.

Além da participação na construção da Marcha da Maconha de São Paulo e a promoção de debates e atividades que integram a comunidade, a Associação Cultural Canábica de São Paulo promove o congresso online sobre maconha. Em relação ao ciberativismo, a principal ferramenta utilizada é o Facebook, onde há o compartilhamento de informações sobre eventos, publicação de textos e vídeos críticos relacionados às substâncias psicoativas. É perceptível a presença dos marcadores de classe, raça e gênero nas discussões propostas na rede social, relacionando com as consequências do proibicionismo. Entretanto, não há discussão sobre os familiares dos usuários, restringindo-se apenas aos consumidores que, majoritariamente, fazem o uso recreativo e social.

A associação Psicodélica Brasileira, com sede no Rio de Janeiro, também apresenta particularidades quanto às substâncias discutidas. Formada em 2015 por usuários, profissionais, pesquisadores e simpatizantes, discute sobre o uso e usuários de psicodélicos, tornadas substâncias ilícitas. Dessa forma, adota um posicionamento antiproibicionista, pró regulação e pró-redução de danos, defende os diferentes usos dessas substancias, espiritual, terapêutico, para estimular empatia, criatividade, prazer, e tem como objetivo fomentar a rede de comunicação para desenvolver novas tecnologias de cuidado em saúde mental, relacionando o conhecimento cientifico com o conhecimento dos usuários.

Dispõe no campo virtual de artigos e textos sobre redução de danos com psicodélicos, além de organizar debates e ações políticas sobre as substâncias psicodélicas e seus diferentes usos. É responsável também por organizar as alas psicodélicas da Marcha da Maconha no Rio de Janeiro. No Facebook ocorre o compartilhamento sobre diferentes temas que se correlacionam com substâncias psicoativas, passando por discussões como legalização da maconha, importância do uso terapêutico de algumas substancias, ações de redução de danos, mensagens reflexivas, socialização de eventos e manifestações. 


\section{CONQGEESSOCIENCIAESOCIEDADE

ANAIS CBCS 2019 | 3 a 5 de outubro de 2019 | Centro Universitário Santo Agostinho - Teresina - PI

A última associação analisada foi a Associação Brasileira de Alcoolismo e Drogas, localizada no Rio de Janeiro. Seminários, encontros mensais, cursos e palestras em escolas e empresas são algumas das atividades realizadas, além do desfile "Alegria Sem Ressaca", onde é pontuada a importância da prevenção à dependência química, demonstrando que não há necessidade de uso ou abuso de drogas para diversão. A associação apresenta ligação com importantes programas universitários de ensino e pesquisa da Universidade Estadual do Rio de Janeiro e Universidade Federal do Rio de Janeiro, o que possibilita maior articulação na organização das atividades.

O site da $A B R A D$, único meio de comunicação virtual, é bastante simples e não apresenta muitas postagens, mas disponibiliza projetos, artigos científicos, depoimentos e linhas de ajuda para fortalecer a geração de conhecimento. Apresenta também uma agenda de atividades, porém a mesma deixou de ser atualizada em 2015.

Dessa forma, das seis associações analisadas, somente uma (Associação Brasileira Comunitária para Prevenção do Abuso de Drogas) não possui site informativo, e duas (Associação de Defesa da Saúde do Fumante e Associação Brasileira de Alcoolismo e Drogas) não possuem alguma rede social, mas todas exercem ou exerceram, em maior ou menor grau, o ciberativismo, mesmo que alguns sites ou redes sociais encontrem-se desatualizados e sem movimentação.

\section{CONSIDERAÇÕES FINAIS}

A organização política dos sujeitos no formato de associações de usuários de substâncias psicoativas fortalece a participação social e proporciona uma nova voz nas discussões relacionadas às substancias psicoativas e aos direitos dos consumidores. Vasconcelos (2007), ao fazer o levantamento das associações de familiares e usuários da saúde mental no Brasil, destacou a parca presença desses grupos na internet, realidade ainda presente mais de uma década depois da pesquisa, destacando-se a escassa quantidade de associações que possuem sites ou redes sociais, sendo comum a desatualização e inatividade dos que já foram criados. É possível que essa pouca 
ANAIS CBCS 2019 | 3 a 5 de outubro de 2019 | Centro Universitário Santo Agostinho - Teresina - PI

participação seja consequência das dificuldades estruturais, econômicas, de renovação de quadros, continuidade de militantes, e fragilidade na organização política, já mencionadas por Amarante (2001), Rosa (2017) e Vasconcelos (2007).

Outro ponto destacado nas análises de Rosa (2017) é que apesar da pouca interlocução entre os diferentes grupos de associados, as associações conseguem proporcionar visibilidade às suas demandas especificas. Criar associações de usuários da saúde mental em torno de enfermidades específicas estende-se às associações de consumidores de spa. Dessa forma, as associações geralmente são criadas em torno de certas substâncias, discutindo sobre os direitos dos usuários de forma fragmentada, ao tempo que possibilita também a diversidade nos tratamentos aos dependentes.

Em relação ao ciberativismo, as associações pesquisadas exercem as funções já apontadas por Queiroz (2017): "dinâmica de recrutamento e dinâmica de difusão de informação" (p. 04). Assim é possível perceber a presença de postagens socioeducativas que propiciam o debate a partir de aspectos sociais, além de seções para filiação e doação na maioria das associações. Discussões pautando aspectos sociais e raciais são mais comuns nos grupos que tem posicionamento claro contra a Guerra às Drogas. Entretanto, não há interesse em discussões sobre a importância da participação da família no processo de desinstitucionalização e garantia de direito desses sujeitos, visto que não há organização ou citação de atividades sobre o tema em nenhuma associação analisada, evidenciando que mesmo que as associações sejam mistas, os interesses que prevalecem são os dos usuários.

É importante destacar que o ciberativismo não limita as ações desses grupos, pelo contrário, serve como mecanismo de ampliação do alcance, visto que todas as associações realizam atividades que interferem no cotidiano social, como debates, rodas de conversa, manifestações, e o ciberativismo possibilita a divulgação dessas atividades, além da difusão de ideias contra hegemônicas, utilizando o mundo virtual para gerar novas visões de mundo e, consequentemente transformações na realidade social. 


\section{CONQGEESSOCIENCIAESOCIEDADE \\ Inovação, Diversidaale e Sustentahilitidade}

ANAIS CBCS 2019 | 3 a 5 de outubro de 2019 | Centro Universitário Santo Agostinho - Teresina - PI

\section{REFERÊNCIAS:}

AMARANTE, P. Associações civis em saúde mental no Rio de Janeiro: democratizando os espaços sociais. Cad. Saúde Pública. Rio de Janeiro, jul-ago, 2001. p. 933-939

AMARANTE, P. O homem e a serpente: outras histórias para a loucura e a psiquiatria. Rio de Janeiro: Fiocruz, 1996.

ARBEX, D. Holocausto Brasileiro. 1. ed. São Paulo: Geração Editorial, 2013

BRASIL, Ministério da Saúde. Saúde Mental no SUS: Os Centros de Atenção Psicossocial. Brasília: Ministério da Saúde, 2004.

COSTA, A. O. A luta por direitos: os caminhos para a implementação de políticas de álcool e outras drogas na Bahia. In FILHO, A. N; MACRAE, E; TAVARES, L. A; RÊGO, M; NU-EZ, M. E. (Orgs). As drogas na contemporaneidade: perspectivas clínicas e culturais. Salvador: Edufba: CETAD, 2012. p. 405426

MILHOMENS, L. Entendendo o ciberativismo sem terra na nova esfera pública interconectada. 2009, Dissertação (mestrado em Comunicação) do Programa de Pós-Graduação em Comunicação, Universidade Federal da Paraíba, João Pessoa, 2009.

PINHO, J B. Jornalismo na Internet: Planejamento e produção da informação on-line. São Paulo: Summus, 2003.

QUEIROZ, E. F. C. Ciberativismo: a nova ferramenta dos movimentos sociais. Panorama. Goiânia, v. 7, n. 1, p. 2-5. Jan./jun. 2017.

ROSA, L. C. S. R. Classes sociais, gênero e etnias na saúde mental. Teresina: EDUFPI, 2015.

ROSA, L. C.S.R. Ganhos na ação em rede a partir das associações de familiares na saúde mental. In (Org). Serviço Social, saúde mental e drogas. Campinas: Papel Social, 2017. p. 141159.

VASCONCELOS, E. Perfil das organizações de usuários e familiares no Brasil, seus desafios e propostas. Cad. Bra. Saúde Mental. Vol 1. N¹. Jan-abr, 2009. 